\title{
Participation and Children's Rights: A Case Study on the Role of Non-Governmental Organizations Working For Internally Displaced Children in Khartoum-Sudan in Health Services ${ }^{1}$
}

\author{
Azza O Abdelmoneium ${ }^{1}$ \\ ${ }^{1}$ Doha International Family Institute/ Qatar Foundation. \\ Correspondence: Azza O Abdelmoneium, Doha International Family Institute/ Qatar Foundation.
}

Received: November 17, 2015

Accepted: December 1, 2015

Available online: December 7, 2015

doi:10.11114/ijsss.v4i1.1202

URL: http://dx.doi.org/10.11114/ijsss.v4i1.1202

\begin{abstract}
Non-Governmental Organizations use a participation approach, claiming that the approach helps communities in the improvement in the lives of the poor. The Convention on the Rights of the Child (article 12) gives children the right to participate and NGOs should involve children in decisions that affect them.

This paper focuses on the work of a national organization working in health services for displaced children in Wad-Elbashir camp in Khartoum-Sudan and argues the case for a rights-based approach to participation in health services, including separate provision of services for adolescent mothers, along with education on sexual and reproductive health for children.

As evident throughout this paper, children's rights to survival and development are not fulfilled and actively undermined by NGOs. This, in turn, affects maternal and child health as the organisation neglects many factors that can contribute to children's health and survival.
\end{abstract}

Keywords: children, rights, participation, health, non-governmental organizations

\section{Introduction: Internally Displaced Children in Sudan}

Since independence in 1956, Sudan has faced severe crises of war and natural disasters, affecting the population and causing deterioration in the political, economic and social status of the country. Almost six million people were displaced within and outside of Sudan (World Fact Book, 2015:11); most being women and children. Displaced children are vulnerable and face many challenges in meeting their basic needs. The voices of displaced children in Sudan are not heard and their rights are not fully met. One of the important rights for children according to the Convention on the Rights of the Child (CRC) is health.

The UN Convention on the Rights of the Child (CRC) not only defines children as persons with rights, but defines an additional set of entitlements for children on the grounds of children's evolving capacities and particular need for protection and care. However, without a rights-based perspective, the language of compassion and charity can diminish children's capacities rather than enhance them (Collins et al, 2002). Health care for children should aim at promoting their survival and development by ensuring the fulfilment of the basic principles of non-discrimination, taking care to realise the best interests of the child, ensuring children's participation and progressively improving levels of service available. The need for children's participation has historically been neglected, but children have unique insight into their own problems and solutions. There are pragmatic as well as moral imperatives for the application of this framework, particularly among vulnerable populations whose exposure to human rights abuses creates particular risks for their health. Non-government organisations (NGOs) play an important role in facilitating children's health, but are they taking a rights based approach, and are the children given the chance to participate according to article 12 in the CRC? In this paper I will analyze the participation of teen mothers who are learning about sex, pregnancy and family planning either for the first time or has attended in health education sessions carried out by the Sudanese Red Crescent

\footnotetext{
${ }^{1}$ Disclaimer: The paper reflects the personal opinion of the author and is not necessarily endorsed by the Doha International Family Institute.
} 
organisation in Wad Elbashir camp in Khartoum.

\section{Rights Based Approach to Health Education}

Rights-based approach is an approach to development used by non-governmental organizations to achieve a positive transformation of power relations among the various development actors. Right based approach is important because it emphasizes the centrality of power relations, and the core principles of participation, accountability and non-discrimination (Gruskin et al, 2010).The health of internally displaced children is poor, with epidemic diseases, anaemia, skin problems and sexually transmitted diseases prevalent ( al-Bathani, 1998). The infant mortality rate as a whole is 56.8 deaths per 1000 live births (males) and 45.9 (females) (World Fact Book 2015).

Sudanese girls may be confronted with the effects of genital mutilation, pregnancy at a young age, or cultural limitations to their access to health care. Displaced girls risk rape and a third of children in the camps work as tea sellers, domestics, scavengers and/or prostitutes in order to support themselves or their families (Loveless,1999). The difficulties of combining work and education, and the expense of education causes most children drop out of school in order to support their families and themselves.

In the poor and violent camps the risk of AIDS/HIV infection, especially for girls, is high. There are 20,000 Sudanese children under fifteen infected with HIV (United Nations AIDS,2004:1). The lack of regular follow-ups means an increased risk of infection and other health problems for these children. Furthermore, AIDS/HIV education is severely limited among this population. $78 \%$ of displaced Sudanese have never received AIDS education, $60 \%$ have not heard of condoms and only $5 \%$ have used them, even though at least $25 \%$ of sexual intercourse takes place outside marriage (Ahmed, 2004).

Over the last 10 years there has been a shift from a 'needs based' to a 'rights based' approach. A needs approach works towards "outcome goals and recognises needs as valid claims. Empowerment is not necessary to meet all needs and it accepts charity as the driving motivation for meeting needs" (Ljungman, 2004:7). A need approach does not encompass the empowerment of children, nor does it address the structural causes of the problem, it focused on charity and dealing with immediate problems. A rights based approach to health care in general has certain underlying principles: (i) non-discrimination (everyone has the right to health education, healthcare and health provision); (ii) participation (the right to express views and for those views to be taken into account); (iii) progressive realisation - an intention on the part of service providers to improve provision to the maximum extent of available resources; (iv) health services offer the best interests of children and (v) contribute to the realisation of a person's rights to life, survival and development (World Health Organization \& Office of High Commissioner of Human Rights, 2008). A rights based approach is holistic, encompassing the economic and political rights that affect the right to health. People in need are not seen as the objects of charity, but instead having rights, are empowered to claim those rights and take an active part in projects and decisions affecting their lives. States ratifying human rights conventions have legal and moral obligations and are accountable for their progressive realisation. Moreover, NGOs are crucial for implementing a rights based approach which uses participation as one of its principles.

\section{Non-Governmental Organizations and the Concept of 'Participation"}

Non-Governmental Organizations (NGOs) are not for profit organizations and claim that participation is a tool they use in working with communities which result in the improvement in the lives of the poor (Tendler, 1982); (Clark,1997). There is now a common understanding that active participation of beneficiaries is crucial to the success of health care services at all levels rather than on the availability of technology, inputs or credit (Patil,1985:29, Garforth,1982).

Patil (1985) suggested the following steps must be taken to make participation possible: awareness, interest identification and organisation. Awareness is a prerequisite to bring about meaningful dialogues between policy makers and beneficiaries. Interest might vary considerably between donors, NGO agents and beneficiaries, so it is important to identify with the interests of the beneficiaries first. Organisation of the community is equally important in a successful participation process, so examining how these services, often designed for adults can be applied to children. For example the involvement and participation of the children in the design, implementation and monitoring of health project that interests them.

The CRC states children have the right to participate (article12), which NGO's also view as an important tool. It "implies joint ownership of the decision-making process and active involvement of all parties, whereby power is shared" (Miller,1997:6, United Nations Human Rights Officer of the High Commissioner, 2015). In practice, this is difficult to implement. Children, being minors, are not easily accepted as decision makers even in a participatory form. The various levels of participation specified by Miller (1997:6-7) going from children simply following directives with explanation or understanding to be involved as equal partners in the decision making processes, the initiation, implementation and evaluation of projects intended for their benefit, provide a tool to assess the level of children's participation in the health 
project of SRC.

By observing the projects in everyday practice and listening to the children I have examined the level at which children participate in decision making and claim their rights, compared to the role of medical doctors, staff and guardians. Participation enables children to develop skills and increase their confidence and self-esteem. It also help them understand the situation, their rights, the possibilities and restraints, and increases their sense of responsibility (Miller,1997:16).

I examined communication processes between NGOs and children, paying particular attention to the actual decision-making of children. The communication process needs to be two-way, to take place in small groups, in the presence of skilled and professional communicators and to have a feedback system (Patil,1985:34). If such a feedback is not possible or ignored it could give the participants the feeling that the programme is imposed on them, leading to indifference and a low level of involvement. In assessing children's participation I will look closely at children's opinions of how they can communicate and their communicators, the organisation's reaction to their views and whether there is a feedback system in place and functioning, using participant observation method which was one of the methods that I used in conducting this research.

\section{Research Methods}

Utilizing a qualitative approach, using mixed methods of interviews, focused groups and participant observation. This fieldwork study interviewed 35 children from a population of 100,000 in Wad Elbashir camp over an 8-year time span. Five focused group discussion was conducted making a total of 58 children between the ages of 10-18 years. Fieldwork carried out from January 2004-January 2005 and back again in 2008 funded by the Netherlands Organisation for Scientific Research and Radboud University of Nijmegen. In addition, field work was conducted in 2012 with Save the Children Sweden for a child situation analysis project. Here I concentrate on the data from one camp, Wad Elbashir.

The consent of the children was obtained, but due to the need for them to be able to speak freely of their rights and needs and to express their opinions of adults and organisations, no formal consent was asked from the guardians, although they were generally informed about the research on request. Interviews were held in a place where parents or NGO staff could not interfere.

With a population of over 100,000, Wad Elbashir is one of the largest camps for internally displaced in Khartoum. Conditions in the camp are extremely harsh .houses are made of waste and mud, there is no electricity, water is supplied by donkey-carts and is very expensive, locations are scattered and services were minimal. A result of the camps being demolished for re-planning.

Following interviews and focus group discussions, recordings were transcribed and analysed based on the theoretical considerations of the right based approach and the policy of the organisation.

\section{Sudanese Red Crescent Project in Wad Elbashir Camp}

There are three health centres in the camp supervised and managed by NGOs but staffed chiefly by displaced persons (Humanitarian Aid Commission,2001). However services are insufficient, for example Medicine is rarely available, necessitating patients making a long journey to the city to obtain it. Until 2003 treatment and medication in the camp were free, but due to new state policy, charges have been instituted, making this a major problem for children and their families. Very few children can afford the charges for medical treatment, and children under twelve must always be accompanied by an adult when being treated: this poses a problem, as most displaced children either live alone or with relatives who are unable to accompany them to the health centre.

Within the camp, Sudanese Red Crescent (SRC) is responsible for an area with approximately 25,000 people and runs one of the three health centres. SRC, active in Sudan since 1957, aims at providing non-discriminatory assistance in crises and initiate programmes based on local needs, long-term development and sustainability. The CRC is not specifically mentioned in its mandate, but SRC is a signatory to the code of conduct for the International Red Cross and Red Crescent that advocate a rights-orientated approach.

The organisation's health centre has the capacity to see 3,000 outpatients a month, open six days per week from 8-4pm. Its main concern is reducing child mortality and morbidity, so they concentrate on lactating and pregnant women and children under five. Men and children over five are not included in the indicators for success in the proposal for 2004. There is no licensed medical doctor on the staff. Training for staff, including a midwife and medical assistant, is provided both through on-the-job coaching by the organisation and specific refresher courses. In spite of its declared policy of reacting to emergencies, there is no provision for dealing with urgent cases of sickness or accidents during the night or at holiday times.

One of the most important activities of SRC is community health promotion to disseminate information and to promote 
health education. The twenty Community Health Promoters (CHPs), with qualifications in social work, management or education, focus on the prevention and early treatment of disease by home visits and providing health and hygiene education, but school visits have ceased due to lack of funds. The health education information is disseminated by conducting health education sessions at the health centre every Thursday of the week for one hour for pregnant and lactating women.

\section{The Practice}

The following examples illustrate the difficulties faced by younger women attending the weekly lectures for pregnant and lactating women (The names of the interviewees have been changed). The average age of marriage among the displaced girls is eighteen, but marriage at eleven is legal for females under Muslim law (Ibrahim et al2006:54). Seventeen year-old Samira, the fourth wife of a man in his late 40s, is illiterate and does not speak Arabic very well. She was circumcised at fourteen, married at fifteen and gave birth at sixteen. Pregnant a second time, encouraged by CHPs and with her husband's approval, she attends sessions regularly, but even with the third wife as translator she has difficulties. She would like to be free to attend school and be with girls of her own age:

"Sometimes I didn't understand what the man said to us. He talks a lot and gives us much information about the baby, but I do not understand what he says... there are things like how to stop getting babies I do not understand. The other women are older than me and they have much more experience in pregnancy. Sometimes I am too shy to ask questions of the male mentor. So I ask the other women, but they do not pay much attention to me. They say to me you are adult now and should be able to understand by yourself. Most of the times I just go and listen because if I do not go they will not give me the flour and sugar for the baby"

Other pregnant and lactating girls, some as young as fifteen, reported difficulties although they received much useful information. Language is a hindrance for non-Arabic speakers; shortage of time and opportunity to ask questions add to the lack of understanding. These are problems faced by seventeen-year old Christine. In a focus group discussion held in June 2004 at Wad Elbashir camp she said:

"I have a problem of communicating with the health promoter and the other women in the session. Several times I tried to tell the promoter that I cannot understand, but the older women in the session do not give me a chance to say so. Sometimes I feel shy about asking questions. The older women communicate and understand better, some of them even attended these sessions before, I feel neglected.... Some promoters just give the session without even asking us if we have questions or not. I feel like I need to know many things in taking care of children and pregnancy."

Other girls complained that there is no information available on family planning or care for children over the age of five. I asked Christine about whether she knows about family planning and safe and unsafe sex. She replied:

"I do not know of family planning, as this is my first baby and the health promoters did not teach us about family planning. The information they give us is about the food for the baby and how to have a safe pregnancy and delivery."

Many would prefer a female lecturer, as they are too embarrassed to question a man. Mary, an 18 year-old, said

"I feel better if we have a female promoter to give us the sessions because I can ask her questions and will not feel shy to do so".

These young women agreed that they would prefer sessions with mothers their own age, rather than with older women, and would value the time to ask questions.

\subsection{Participation and Health Education Sessions}

At the time of the study, there were no sessions on sexual and reproductive health for men or children. There were sessions on STI, but not sexual violence, abortion, sexual needs, sexuality or family planning. Husbands do not take part in the health education sessions provided for pregnant or lactating women.

Mary became pregnant with her second child within nine months of the birth of her first. She had no knowledge of family planning or contraception, nor was she told to prevent or delay a second pregnancy. Sabah, eighteen, has two children and in the three years she has attended the centre had never heard of contraception or family planning. All adolescent boys and girls, who were interviewed, complained about the deficiency in health education, especially in the area of sexual and reproductive rights. When I mentioned AIDS or HIV, the majority of the children had heard of them, but not recently. Kawja, an eighteen-year old boy, said:

"The last time I saw a video on AIDS was in 2001. They showed us the video at the health centre. It was about AIDS and how people get sick and what we should do to avoid it." 
Health education for children and adolescents in the camp is confined to awareness sessions on malaria, avoidance of diseases and dental care. The children are appreciative of the lessons in hygiene, but none of the young people I interviewed had attended sessions on sexuality or reproductive health and were embarrassed by the subject. Some children who did not attend school, such as Kamal and Fatima, both fifteen, had never heard of AIDS. Kamal confessed,

"I never heard of AIDS. I know malaria and meningitis but not AIDS." Fatima, said, "I have not heard of AIDS and I do not know what it is."

Rena, fifteen, said, "Last year someone from the organisation came and told us not to take dirty things from the floor like razors, pins, etc and not to play in dirty water."

Kholowd said: Last year two men came to the school and talked about houseflies and that we have to cover our food and not leave the house dirty. They told us not to walk under the sun too much."

Most school children received some health education, but not recently, those not attending school have little opportunity to attend such sessions. None of the children with whom I spoke knew anything about reproductive rights and health. Reproductive rights, AIDS/HIV, sexuality, contraception are rarely discussed with the children at the camp.

Seventeen-year old Ahmed, goes to school and works as well. He said:

"Teacher Fathi gives us awareness sessions on AIDS and how to prevent it. He described what AIDS and sexual intercourse are, and that we should not have sex without protecting ourselves. He also described to us how to clean ourselves and our houses. That was last year. This year he did not give us any sessions."

These health education sessions were based on monologues: the health promoter just gives the information and leaves. Awatif, sixteen, reported,

"The man who came from the SRC talked about AIDS and other diseases. He asked us questions and we answered, but did not give us a chance to ask him anything."

\section{Analysis and Discussion/ Policy Implications}

It is clear that children are rarely given a chance to engage in any of the decisions or discussions that concern them. The important issues of reproductive health are not adequately transmitted to them. Children are given no chance to engage in a dialogue, limiting access to appropriate information that could protect them from harmful infections, diseases and unintended pregnancies. With the exception of Ahmed, none of the girls or boys said that AIDS could be transferred through sexual intercourse. When I discussed this with the girls they laughed or became embarrassed. Aida, fifteen, said to me, "It is aib (meaning shameful) to talk of sex. I do not know that AIDS can be transferred through sex." Children are defenceless and open to infection, since they have no way of knowing how to prevent it. This is extremely important, as children in the camp are sexually active. Because the permissible age for marriage is 11, children need knowledge and information about sexually transmitted diseases, including AIDs, and this is not reaching them.

Children need information on sexual development and sexuality (including puberty), sexually transmitted diseases HIV/AIDS and unsafe sex practices that can lead to unwanted pregnancies or STDs, but this is lacking in the activities of the organization. Some of this information might be given in secondary schools but not primary schools, but most of the children and adolescents in the camps are unable to attend secondary school. The organisations can play a much greater role in disseminating this information in order to prevent diseases and unwanted pregnancies. It would seem that health promoters omit mentioning that AIDS is sexually transferred, feeling it shameful and embarrassing to talk of sex with the children. Such attitudes can limit the transmission of information.

\subsection{Discussion/Policy Implications}

There is a discrepancy between stated policy and implementation, and a degree of discrimination. The policy of the organisation encouraged the participation of the community, but in reality young people, particularly girls, and children were given less room to participate: they are not included in the initiation or implementation stages. With special emphasis on mothers and children under five, men and older children are not involved in the drive to increase the health and hygiene of the community, there is lack of communication within the targeted group.

Women, in general, are not treated as persons in their own right, but simply as responsible for the health of the next generation. Information is given to a passive audience: dialogue and discussion are rare. This is particularly true for inexperienced teenage mothers. In the sphere of sexual and reproductive rights, they, like other women, have their own interests and bodily autonomy ignored. There was no programme of family planning, and women were advised on an irregular basis. The health promotion project cannot be sustainable when men, frequently the cause of women's disempowerment and vulnerability, are not targeted.

Women, and more particularly girls, are unaware of their rights and see themselves as incapable of independent action. 
Female Genital Mutilation (FGM) is a violation of human rights and a health risk. SRC's programmes to abolish harmful traditional practices appears inadequate, and in particular awareness sessions for boys and men in relation to such practices is lacking. While the organisation focuses on women and young children, the most vulnerable members of the IDP community, the differing attention given to both age and sex can have an impact on applying a systemised gender approach in development.

The traditions and beliefs in the camp limit women's engagement in discussion with men. Young women are too shy to enter any discussion that might occur. Most women and all children under eighteen are excluded from the decision-making sphere.

The determination and recognition of differing needs and interest identification according to age is lacking in the reproductive health care offered. Children and adolescents, particularly girls under eighteen, can be raped, marry early or have sex before marriage, with the consequent risks of infection and pregnancy: the subsequent wrath of their family leads to exclusion, and they are left to take complete responsibility for themselves and their child.

SRC seems to fail to realise the importance of teaching adolescents about sexual and reproductive health. Adolescents need support and care if they are to develop into physically and socially mature adults, able to make informed and responsible decisions (World Health Organization, 2015). In the camps their chances of education and health education are minimal. Children might have heard of AIDS, but forget about it soon. Organisations such as SRC can play a much greater role in preventing diseases and unwanted pregnancies. No regular follow-up means an increase in the risks of infection and problems for HIV positive children and those living with AIDS. Even the most rudimentary treatment for such diseases is lacking. Children, especially between ten and eighteen, are the most vulnerable to diseases such as HIV/AIDS. The lack of participation and dialogue means that the information given is less likely to be retained, and there is no written information through which the children, even if literate, could increase their understanding which would serve to remind them of what they had been told.

Children are not treated as active participants in their own health education but as disaster victims, rather than involved and knowing subjects: they are not allowed to participate in the project appraisal or application. In the formal health education sessions for pregnant and lactating women, dialogue and a participatory approach were hardly used. On home visits the health promoter would ask women about their health but not engage in a discussion. Women seldom volunteered information, although they might ask questions about health. Children over five are not involved in health education sessions, home visits and other activities of SRC. There are no direct courses or training for them in relation to their health rights.

If children were given respect, allowed to participate, their skills would develop and their empowerment increase. In reality children are badly treated by the organisation; their identity as human beings who have the right to express themselves and freedom of choice is denied.

"Participation is a way to the empowerment of the poor. Participation is both a road to and an outcome of empowerment" (Abdelrahman, 2001:73). This road is denied to children. The specific exclusion of children from target groups in project proposals, in the dissemination of information and in treatment means that the rights and needs of children are ignored. No health education sessions were targeted at children. It can be said that the level of participation of children is that of manipulation.

\section{Conclusion and Recommendations}

Despite Sudan's ratification of the CRC, the implementation, monitoring and enforcement of these human rights treaties are inadequate. Practice by the Sudanese state and by NGOs falls far short of non-discrimination, the best interests of the child, progressive provision and children's participation. As a result, children's rights to survival and development are not fulfilled and actively undermined. This affects maternal and child health as the organisation neglects many factors that can contribute to children's health and survival. The extreme poverty of camp life, and the frequent absence of a male provider forces many mothers to work long hours for low wages outside their 'home', and that can have a negative effect on the health of mothers and children. The organisation does not appear to consider alternatives such as encouraging mothers to know their reproductive rights and limit the number of children. Important issues in reproductive health, such as family planning, sexuality, rape, precocious marriage and pregnancy, birthing customs or harmful practices like genital mutilation, receive scant attention. The organisation look at women mainly as child-bearers and carers and not as people seeking health, and be advised on, their own reproductive health care. Limiting their target population to pregnant and lactating women and children under five, excluding men and older children is no guarantee of gender equality in health. The same is true of the health rights of women and men, because although separate services are required for different age and gender groups the provision (or lack of provision) of education and health services for one group affects others. 
I would recommend that the organisation follows a rights-based approach, including participation in health services. Community awareness of the importance of children's rights to education on sexual and reproductive health needs to be raised. If children were involved in the design and evaluation of services for young mothers, as opposed to mixed-age groups, the outcome would be better for both infants and mothers. An increase in the active participation of children in health education sessions would be of enormous benefit. A more protective and supportive health system, backed by an increase in the state health budget and staff trained in gender and rights-based approaches would encourage children to seek medical treatment and enhance sustainable development of the health project. By involving children in the activities of the organisation and hearing their voices the efficacy of services would be increased.

\section{Acknowledgement}

This study was funded by the Netherland Organization for Scientific Research in the Netherlands.

\section{References}

Abdelrahman, M. (2001). State- Civil Society Relations: The Politics of Egyptian NGOs. The Hague: Shaker Publishing.

Ahmed, S. (2004). Situation Analysis-Behavioural Survey Internally Displaced People Results and Discussions. Khartoum: Sudan National Aid Control Program (unpublished report).

Al-Bathani, E. (1998). A Study of Urban Problems. Khartoum: Oxfam (unpublished study).

Clark, J. (1997). "The State, Popular Participation and the Voluntary Sector". In: David Hulme, Michael Edwards (eds). NGOs, States and Donors Too Close for Comfort. New York: St. Martin's Press, 43-58.

Collins T., Landon, P., \& Caroline, D. (2002). "Rights-Based Approach". www. Sen.parl.gc.ca/pearson/ (accessed 15 April 2007).

Garforth, C. (1982). "Reaching the Rural Poor: A Review of Extension Strategies and Methods". In: Gwyn E.Jones, Maurice.J.Rolls (eds). Progress in Rural Extension and Community Development. New York: John Wiley and Sons, 43-70.

Gruskin, S., Bogecho, D., \& Ferguson, L. (2010). Rights-Based Approaches to Helath Policies and Programs: Articulations, Ambiguities, and Asessment. Journal of Public Heath Policy, 31, 129-145. http://dx.doi.org/10.1057/jphp.2010.7

Humanitarian Aid Commission( 2001). Summarized paper about camps in Khartoum and the organizations that are working with the displaced. Kh artoum: Humanitarian Aid commission (unpublished paper).

Ibrahim, B., \& Alyce, A. (2006). "Child Marriage". In. Encyclopedia of Women and Islamic Cultures. Volume III. Family, Body, Sexuality and Health, Suad J (ed). Leiden: Koninklijke Brill Nv.

Ljungman, C. (2004). Applying a Rights-Based Approach to Development: Concepts and Principle, Conference paper : The Winners and Losers from Rights-Based Approaches to Development. Retrieved from http://www00.unibg.it/dati/corsi/68028/51819-Ljungman\%20\%282004\%29\%20Applying\%20RBA\%20to\%20dev elopment.pdf.

Loveless, J. (1999). Displaced Populations in Khartoum: A Study of Social and Economic Conditions. London: Save the Children Denmark.

Miller, J. (1997). Never too Young . A Handbook for Early Years Workers. London: Save the Children.

NCCW (National Council for Child Welfare)( 2002). Additional Information to the UN on the Rights of the Child. Khartoum: National Council for Child Welfare (unpublished report).

Patil, R. (1985). "The Role of Development Communication in Active Participation of the Poor in Rural Development Programs in India". In: Ouchi Minoru; Campbell, M (eds) Development Communication and Grassroots Participation. Maylysia: Association of Development Research and Training Institutes of Asia and the Pacific, 23-42.

Tendler, J. (1982). Turning Private Voluntary Organisations into Development Agencies: Questions for Evaluation. Program Evaluation Discussion Paper 12.Washington, D.C: US.Agency for International Development. Retrieved from http://pdf.usaid.gov/pdf_docs/PNAAJ612.pdf.

United Nations and AIDS (2004). Epitemiological Fact Sheets on HIV/AIDS and Sexually Transmitted Disease in Sudan . Retrieved from http://data.unaids.org/publications/fact-sheets01/sudan_en.pdf/.

United Nations Human Rights Officer of the Hihg Commissioner (2015). Convention on the Rights of the Child. Retrieved from http://www.ohchr.org/en/professionalinterest/pages/crc.aspx. 
World Health Organization (2015). Adolescent Reproductive Health. Retrieved from http://www.who.int/maternal_child_adolescent/topics/maternal/reproductive_health/en/

World Health Organization \& Office of the United Nations High Commissioner for Human Rights (2008). The Right to Health. Fact Sheet 31. Retrieved from http://www.ohchr.org/Documents/Publications/Factsheet31.pdf.

World Fact Book, 2015. Sudan. The World Fact Book. Central Intelligence Agency and

Director of Central Intelligence. Retrieved from

https://www.cia.gov/library/publications/the-world-factbook/geos/su.html.

\section{(cc) $\mathrm{Br}$}

This work is licensed under a Creative Commons Attribution 3.0 License. 